Volume 6, No. 2

April - June 2020

www.jrmi.pk

\section{Submitted}

June 5, 2020

Accepted

June 20, 2020

\section{Author Information}

Dr. Maimoona Sardar

Nameen

Medical Officer

Rehman Medical Institute

Peshawar, Khyber

Pakhtunkhwa, Pakistan

(Corresponding Author)

Email:

maimoona345@gmail.com

\section{Laraib Khan}

Final year MBBS student

Rehman Medical College,

Peshawar, Khyber

Pakhtunkhwa, Pakistan

Citation: Nameen MS, Khan

L. Corona pandemic

overshadowing other diseases. [Editorial]. J Rehman Med

Inst. 2020 Apr-Jun;6(2):1-2.

\title{
Corona pandemic overshadowing other diseases
}

Maimoona Sardar Nameen, Laraib Khan

\section{ABSTRACT}

The devastating effects of the Coronavirus 19 pandemic and its implications for human health in the short and long term are presented and discussed in brief with a view to create awareness and elicit suggestions for feasible solutions to the crisis.

The authors declared no conflict of interest. Both authors contributed substantially to the write-up of the editorial, and agreed to be accountable for all aspects of the work.

\section{INTRODUCTION}

Coronavirus Disease 2019 (COVID-19), took the world by surprise in December 2019. The World Health Organization (WHO) announced the COVID-19 outbreak as a pandemic on March 11, $2020 .{ }^{1}$ It caused havoc in all hospitals across the globe as patients showing symptoms were rushed into Emergency Rooms (ER) and Intensive Care Units (ICU) were quickly filled up. This resulted in putting hospitals under pressure to keep a track of how many ICU beds were occupied with patients and the nature of their diseases. ${ }^{2}$ The Journal of The American College of Cardiology stated that the response to COVID-19 can compromise the rapid triage of non-COVID-19 patients with cardiovascular conditions. ${ }^{3}$ The government played a major role here and the general public was given stay-at-home orders ensuing curfews and quarantine. ${ }^{4}$ As a result, patients were deprived of clinical checkups and ended up not going to hospitals even in cases of emergency because of the fear of contracting the virus. 5

Groups that were affected the most included the elderly, young, women of reproductive age, children, and people with pre-existing diseases. ${ }^{6}$ Some major pre-existing diseases to be considered here that can be life-threatening in the COVID-19 scenario are heart diseases, stroke, diabetes, pulmonary diseases, HIV, cancers, diseases that cause disabilities in children and complications of pregnancy.

Emergency Departments (ED) play a critical role in diagnosing and treating conditions that might result in serious disability or death. A research was carried out in the USA which found reductions in numbers of ED visits by males and females in all age groups for three conditions: Myocardial Infarction (MI) 23\%, Stroke 20\%, and Hyperglycemic Crisis $10 \%$. These estimates are consistent with but smaller in relative magnitude than the $42 \%$ overall decline in ED visits observed during the early pandemic period.

In a study conducted in California, USA, the Emergency Medical Services (EMS) reported the highest-ever number of cardiac arrests in the field $(45 \%)$ more than the previous month, suggesting that patients were waiting too long to seek cardiac care. Of note, all of these EMS heart patients tested negative for COVID-19. ${ }^{8}$

A scientific study was done in which the impacts of COVID-19 on HIV, Malaria and Tuberculosis were assessed. According to the results, in settings with high burdens of HIV, tuberculosis, or malaria, disruptions during the COVID-19 pandemic could cause an increase in deaths due to HIV of up to $10 \%$, due to tuberculosis of up to $20 \%$, and due to malaria of up to $36 \%$ over 5 years compared with if no COVID-19 pandemic occurred. $^{9}$ Experts predict an additional 6.3 million cases of tuberculosis infection by 2025 due to attention diverted towards corona treatment. This is based on 3-months lockdown and 10 months restoration of TB services. ${ }^{10}$

Estimates of the effect of COVID-19 on maternal and child health pose a grim picture. ${ }^{11} \mathrm{MNCH}$ services, on the least severe scenario, are projected to decrease by $9 \cdot 8-18.5 \%$ across 118 low to middle income countries, resulting in 253,500 additional child deaths and 12, 200 additional maternal deaths. If sustained, this would have devastating effects on maternal and child health.

From the data of Big Data Observatory Platform for Stroke of China, the total number of thrombolysis and thrombectomy cases dropped $26.7 \%$ and $25.3 \%$ respectively in February 2020 compared to February 2019 based on the dataset collected by 227 stroke centers in China; the hospital admissions for stroke dropped $\sim 40 \%$. $^{12}$

According to a WHO survey from 155 countries, more than half $(53 \%)$ of the countries surveyed have partially or completely disrupted services for treating hypertension; $49 \%$ for diabetes and its complications; $42 \%$ for treating cancer, and $31 \%$ for cardiovascular emergencies. Rehabilitation services have been disrupted in almost two-thirds $(63 \%)$ of countries, even though rehabilitation is key to a healthy recovery following a severe illness from COVID-19. ${ }^{13}$ 
The solution to this problem is interdisciplinary. Telehealth programs should be established for easy communication with the patients. Clinicians should incorporate targeted questioning assessments and should regularly reinforce the indications for seeking medical evaluation. Both in-person and remote care services are of high value. Economic stability is one of the major factors required to be able to do all the necessary changes. Policy changes are required. ${ }^{14}$ Financial security in the form of insurance for the frontline health workers (who are at greater risk), should be introduced. ${ }^{15}$ Countries must ensure that everyone can receive major services including health care, they must invest adequately in social protection programs to keep people safe and to shield them from the consequences of losing their livelihoods. ${ }^{16}$

\section{REFERENCES}

1. Cucinotta D, Vanelli M. WHO declares COVID-19 a pandemic. Acta Biomedica. 2020;91:157-60.

2. As hospitals fill, Florida wants to know who is using the ICU beds - South Florida Sun-Sentinel, https://www.sunsentinel.com/coronavirus/fl-necoronavirus-icu-bed-reporting-ruleschange-20200623dmf4p5nf3few5mvjvh53vixewmstory.html.

3. Driggin E, Madhavan MV, Bikdeli B, Chuich T, Laracy J, Biondi-Zoccai G, et al. Cardiovascular considerations for patients, health care workers, and health systems during the COVID-19 pandemic. J Am Coll Cardiol 2020;75:2352-71.

4. Gostin LO, Wiley LF. Governmental public health powers during the COVID19 pandemic: stay-at-home orders, business closures, and travel restrictions. JAMA. 2020;323:2137-8.

5. COVID-19 fears keep people from hospitals, but doctors say call 911 for heart attack and stroke - $\mathrm{CNN}$, https://edition.cnn.com/2020/04/22/health /coronavirus-hospitals-heart-healthstatement/index.html.

6. Douglas M, Katikireddi SV, Taulbut M, et al. Mitigating the wider health effects of COVID-19 pandemic response. $\mathrm{Br}$ Med J. 369. Epub ahead of print 27 April
2020 .

7. Lange SJ, Ritchey MD, Goodman AB, Dias T, Twentyman E, Fuld J, et al Potential indirect effects of the COVID19 pandemic on use of emergency departments for acute life-threatening conditions-United States. January-May 2020. MMWR Morb Mortal Wkly Rep. 2020 Jun 26;69(25):795-800.

8. Where are all the patients? Addressing COVID-19 fear to encourage sick patients to seek emergency care | Catalyst non-issue content, https://catalyst.nejm.org/doi/full/10.1056/ CAT.20.0193.

9. Hogan AB, Jewell BL, Sherrard-Smith E, Vesga JF, Watson OJ, Whittaker C, et al Potential impact of the COVID-19 pandemic on HIV, tuberculosis, and malaria in low-income and middleincome countries: a modelling study. Lancet Glob Heal. 2020;8:e1132-e1141.

10. Coronavirus lockdown could see 6.3 million more people get tuberculosis $\mathrm{CNN}$,

https://edition.cnn.com/2020/05/06/health /tuberculosis-deaths-lockdown-scliintl/index.html.

11. Roberton $\mathrm{T}$, Carter ED, Chou VB, Stegmuller AR, Jackson BD, Tam Y, et al. Early estimates of the indirect effects of the COVID-19 pandemic on maternal and child mortality in low-income and middle-income countries: a modelling study. Lancet Glob Health 2020 May;8: e901-08.

12. Zhao J, Li H, Kung D, et al. Impact of the COVID-19 epidemic on stroke care and potential solutions. Stroke. 2020;51:1996-2001.

13. COVID-19 significantly impacts health services for noncommunicable diseases, https://www.who.int/newsroom/detail/01-06-2020-covid-19significantly-impacts-health-services-fornoncommunicable-diseases.

14. Reza N, DeFilippis EM, Jessup M Secondary impact of the COVID-19 pandemic on patients with heart failure. Circ Heart Fail. 2020 May;13(5):e007219..

15. Hoda W, Bharati SJ, Kumar A, Choudhary P, Abhishek Shankar A. Socio-cultural and economic impact of corona virus on cancer patients, caregivers and survivors. Asian Pacific J Cancer Care 2020;5:171-3.

16. COVID-19: UN urges ramping up social protection programmes to safeguard those most vulnerable | UN News, https://news.un.org/en/story/2020/08/107 1092. 